\title{
Neumoperitoneo causado por una tuberculosis
}

\author{
Pneumoperitoneum caused by tuberculosis
}

Sonia Martínez ${ }^{1}$, Juan José Arroyo Martín ${ }^{2}$, Begoña Patiño Bernal ${ }^{3}$, Antonio Valdivia Pérez ${ }^{4}$

DOI 10.31837/cir.urug/5.2.1

Recibido: 26 de marzo de 2020

Aceptado: 8 de febrero de 2021

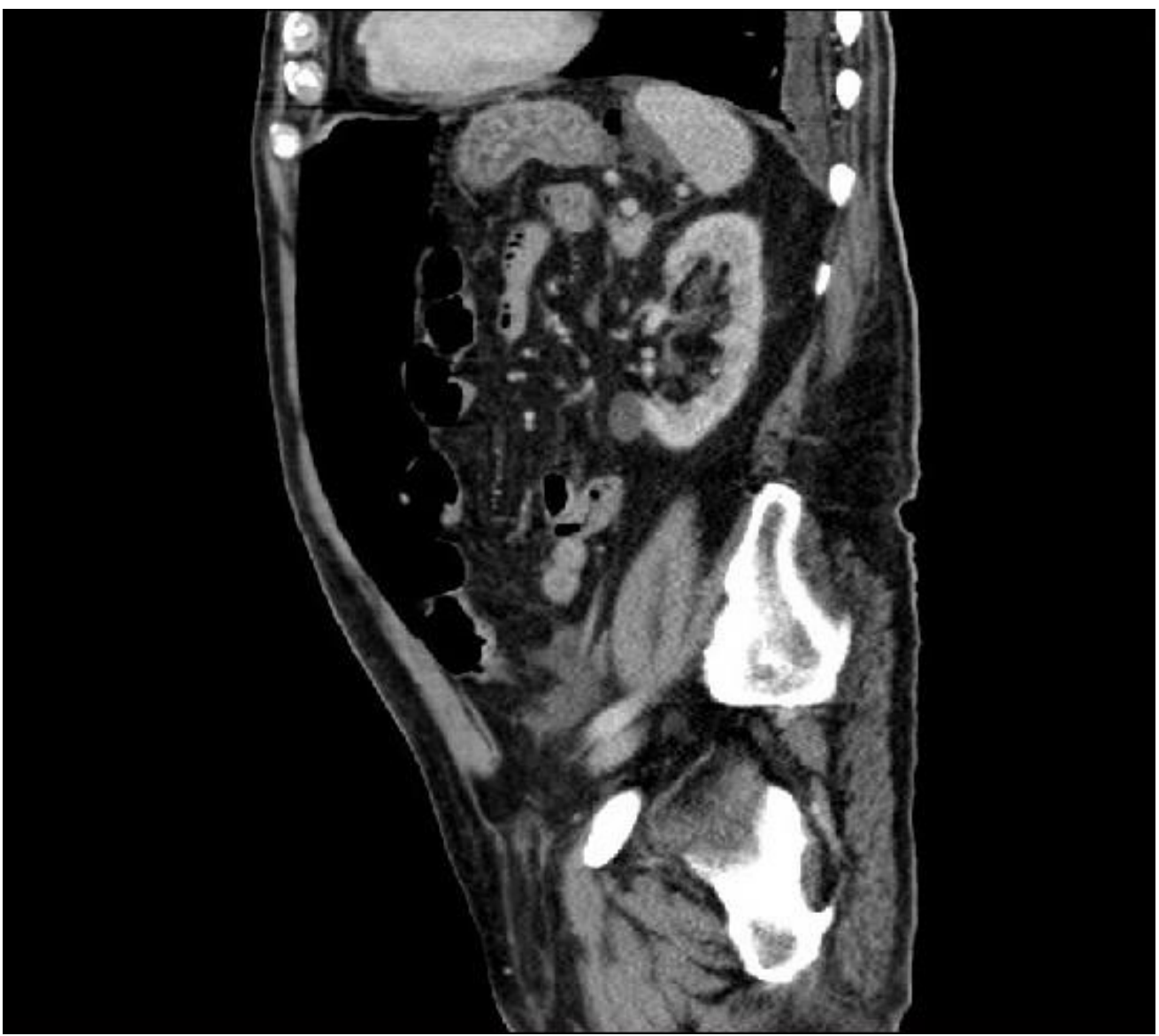

Fig 1. Imagen de TC que muestra neumoperitoneo masivo.

${ }^{1}$ Cirujana general y del aparato digestivo Hospital de la Ribera, Valencia, España, soniacirugia@gmail.com

2 Jefe del Servicio de Cirugía General del Hospital de Denia. Denia. Alicante. España.

${ }^{3}$ Cirujana general y del aparato digestivo en el Hospital de Denia. Alicante. España

${ }^{4}$ Jefe del Servicio de Medicina Preventiva del Hospital de Denia. Denia. Alicante. España. 
Varón de 86 años que acude a Urgencias por edema en los miembros inferiores. A la exploración presenta discretas molestias abdominales, sin otra clínica acompañante.

La analítica muestra una hemoglobina de $8.2 \mathrm{~g} / \mathrm{dL}$ con un hematocrito del $24 \%$. Se realiza una TC de tórax y de abdomen (fig 1) que objetiva nódulos pulmonares bilaterales de apariencia inflamatoria, derrame pleural y neumoperitoneo masivo, sin evidencia de rotura de víscera hueca. Se mantiene a dieta absoluta y se inicia antibioterapia y nutrición parenteral.

Se extraen cultivos, apareciendo mycobacterias en el lavado broncoalveolar. Se diagnostica de tuberculosis diseminada. Se ajusta el tratamiento antibiótico y el paciente mejora progresivamente, siendo dado de alta hospitalaria a los 10 días de inicio del cuadro. En la TC de control a los 3 meses el neumoperitoneo ha desaparecido.

El origen más frecuente de neumoperitoneo espontáneo no quirúrgico es el tórax (por tuberculosis, ventilación mecánica, barotrauma, contusión pulmonar, enfermedad pulmonar obstructiva crónica...), existiendo también causas abdominales como la neumatosis quística intestinal. Entre el 5 y el 14\% de pacientes con neumoperitoneo espontáneo pueden ser manejados de forma conservadora, sin cirugía. Algunas series muestran que hasta en el $44 \%$ de los neumoperitoneos no quirúrgicos no se evidencia perforación visceral. Se trata por tanto de una causa de neumoperitoneo no quirúrgico que con un adecuado enfoque clínico y terapéutico permite evitar una intervención quirúrgica. ${ }^{1,2,3,4,5}$

\section{Bibliografía}

1. Martínez-Hernández-Magro P, Lazarini-Díaz-Barriga JA, Mendoza-Suárez J, LemusSánchez G. Neumoperitoneo no quirúrgico. Anales de Radiología México. 2019;18:207-211. DOI: $10.24875 / A R M .19000106$

2. Martínez-Hernández-Magro P, Lazarini-Díaz-Barriga JA, Mendoza-Suárez J, LemusSánchez G. Neumoperitoneo no quirúrgico. Anales de Radiología México. 2019;18:207-211. DOI: $10.24875 / A R M .19000106$

3. Larrañaga I, Meneu JC, Díaz G, Mendía E, Rey A, Fresneda V. Neumoperitoneo no quirúrgico. Cir Esp. 2000;67:5:411-523. En: https://www.elsevier.es/es-revista-cirugiaespanola-36-articulo-neumoperitoneo-no-quirurgico-10573 
4. Ahmad QA, Sarwar MZ, Fatimah N, Ahmed AS, Changaizi SH, Ayyaz M. Acute Presentation and Management of Abdominal Tuberculosis. J Coll Physicians Surg Pak. 2020 Feb;30(2):129-133. DOI: 10.29271/jcpsp.2020.02.129

5. Kentley J, Ooi JL, Potter J, Tiberi S, O'Shaughnessy T, Langmead L et al. Intestinal tuberculosis: a diagnostic challenge. Trop Med Int Health. 2017 Aug;22(8):994999. DOI: 10.1111/tmi.12908 